\title{
THE PREPARATION OF PARTIALLY PURIFIED PLASMIN, AND AN ACCOUNT. OF ITS INTRATHECAL USE IN PATIENTS
}

\author{
By A. P. FLETCHER 1 \\ (From the Wright-Fleming Institute of Microbiology and St. Mary's Hospital, London W. 2, \\ England)
}

(Submitted for publication February 8, 1954; accepted May 26, 1954)

The treatment of tuberculous meningitis is frequently hindered by the formation of exudate within the cerebrospinal spaces. This exudate may obstruct the cerebrospinal circulation and give rise to the complications of subtentorial, basal cistern, and spinal block. Furthermore, the presence of exudate predisposes to the occurrence of tuberculous arteritis, which is responsible for the cerebral and spinal cord softenings frequently found in this disease $(1-4)$.

Cathie (5) introduced the use of intrathecal streptokinase to prevent the formation of, and to remove exudate. It was hoped that the use of this agent would reduce the incidence of complications, render chemotherapy more effective, and lessen the likelihood of relapse. Clinical trials in tuberculous meningitis with streptokinase have yielded contradictory results (6-9). The majority of investigators believe that its value remains unproven.

Streptokinase has no intrinsic proteolytic properties, but activates a precurser plasminogen to form a proteolytic enzyme plasmin, the action of which may be inhibited by body fluids (10). Streptokinase was used in the treatment of pleural infections by Tillett and Sherry (11), who showed that clinical response was dependent upon the demonstration of adequate fibrinolytic activity in these fluids. Investigators interested in intrathecal treatment have relied upon clinical response to assess the adequacy of the dose, and have for the most part employed a dose of 100 Christensen units (600 Cathie units) of streptokinase for intrathecal use.

The development of methods for the measurement of the various components of the plasminogen-plasmin system in biological fluids (12) led Fletcher (13) to determine the composition of the cerebrospinal fluid with respect to these compo-

1 Present address: Dept. of Medicine, New York University-Bellevue Medical Center, New York 16, N. Y. nents in normal persons, and in patients suffering from tuberculous meningitis. $\mathrm{He}$ showed that although the addition of streptokinase in sufficient quantity to cerebrospinal fluid in tuberculous meningitis would always produce fibrinolytic activity in the fluid, the concentration required was sometimes greater than could be administered to patients for fear of toxic reactions. Moreover, the administration of relatively large doses of streptokinase, shown to be adequate by in vitro testing, frequently failed to produce any free fibrinolytic activity in vivo. The evidence indicated that the irritant action of high concentrations of streptokinase on the meninges was sufficient to alter the composition of the cerebrospinal fluid, and to inhibit fibrinolytic activity. Fletcher concluded that the intrathecal administration of streptokinase was only of limited benefit in tuberculous meningitis, and that its use required close laboratory control.

Hamburger and Biehl (14) using rhesus monkeys have demonstrated that the irritant effects of intrathecal streptokinase produced a marked pleocytosis and a positive Pandy response in the cerebrospinal fluid, although the monkeys remained well.

It seemed that many, although not all, of the difficulties encountered with the clinical use of streptokinase were due to its role as an activator rendering its action entirely dependent upon the composition of the cerebrospinal fluid. The use of the enzyme itself, plasmin, rather than the activator, streptokinase, might be expected to offer certain advantages in therapy. The present communication describes the preparation of partially purified plasmin, and the clinical results following its use in tuberculous meningitis.

\section{MATERIALS AND METHODS}

A single batch of streptokinase-streptodornase ("Varidase" Lederle, No. 7-1089-121A) was used throughout. The relative proportion of streptokinase to streptodor- 
nase was high, each ampule containing 148,000 units of streptokinase and 17,000 units of streptodornase. The methods of measurement for the components of the plasminogen plasmin system have been described in a previous publication (12) and were recorded in Christensen units (15). Nitrogen determinations were made by a conventional micro-Kjeldahl method.

\section{Preparation of plasminogen}

All preparations were kept in the cold room at $4^{\circ} \mathrm{C}$, whilst procedures with ether were carried out at $0^{\circ} \mathrm{C}$. To insure complete precipitation, a period of 12 hours was allowed to elapse between each precipitation step, and subsequent centrifugation, which was performed in an International PR-1 angle head model at $0^{\circ} \mathrm{C}$. Upon occasion, in the absence of ether, the temperature was allowed to rise to $20^{\circ} \mathrm{C}$, to speed the solution of precipitates.

Blood (four to six weeks old) from the bank, preserved in glucose citrate mixture, was centrifuged in an Alfa-Laval model. Bottles showing obvious contamination or gross hemolysis were discarded.

Ether $(100 \mathrm{ml}$.) was slowly added, with stirring, to 1 liter of plasma contained in an ice bath (16). The precipitate was discarded, and a further $150 \mathrm{ml}$. of ether was added to the supernatant, the mixture was placed in a bottle and frozen in contact with solid carbon dioxide (17). Twelve hours later it was thawed at $4^{\circ} \mathrm{C}$, and centrifuged. The precipitate and the fatty ether layer were discarded.

The residue was left overnight in shallow dishes under a fan in the cold room to remove excess ether, and then dialyzed against running tap water for 12 hours. It was then diluted fivefold with distilled water, and the $\mathrm{pH}$ adjusted to 5.3 with 1 per cent acetic acid. The precipitate was taken up into $400 \mathrm{ml}$. of $0.225 \mathrm{M}$ saline, and the $\mathrm{pH}$ adjusted to 7.4 with sodium hydroxide, after the addition of $20 \mathrm{ml}$. of $0.1 \mathrm{M}$ phosphate buffer. This solution was filtered through a Whatman No. 52 paper, diluted tenfold with distilled water, and the $\mathrm{pH}$ adjusted to 5.3. The precipitate was dissolved in $300 \mathrm{ml}$. of $0.15 \mathrm{M}$ saline. If the material was to be freeze-dried the $\mathrm{pH}$ was adjusted to 7.4, the final concentration of phosphate buffer being $0.005 \mathrm{M}$; if the material was to be sterilized the final $\mathrm{pH}$ was 6.7 and the concentration of phosphate buffer was $0.004 \mathrm{M}$.

\section{Sterilization}

Difficulty was encountered in sterilizing the various plasminogen preparations, since adsorption of material on to filter pads, and blocking of filters was frequently encountered. Filter aids (e.g., celite) were not helpful. Material. adjusted to $\mathrm{pH} 6.5$ to 6.7 was centrifuged for one hour at $5,000 \mathrm{rpm}$ in an angle head centrifuge, and then filtered through a Whatman No. 52 paper. The small Seitz filter $(6 \mathrm{~cm}$.) was prepared as follows: 200 ml. of $0.05 \mathrm{M}$ phosphate buffer at $\mathrm{pH} 6.5$, followed by $100 \mathrm{ml}$. of the preparation to be filtered were passed through the filter, and then discarded. Prepared in this manner the filter would now pass 600 to $800 \mathrm{ml}$. of preparation without blocking and without any significant loss of plasminogen.

Subsequent manipulations were performed in a germicidal uiltraviolet chamber. Sufficient buffer to bring the pH to 7.4 was added. The preparation was assayed for plasminogen (it usually contained 400 to 800 units per ml. at this stage) and was diluted to bring it to 100 to 150 plasminogen units per $\mathrm{ml}$. in $0.15 \mathrm{M}$ saline buffered in $0.005 \mathrm{M}$ phosphate buffer. The requisite amount of streptokinase was then added with the temperature at $4^{\circ} \mathrm{C}$, and the material was stored at $-20^{\circ} \mathrm{C}$ in screw capped bottles. The contents were stable for some months. Samples from each bottle, taken prior to storage, were planted into a tube of glucose broth and a tube of chopped meat medium, which were incubated at $37^{\circ} \mathrm{C}$ for 10 days, to test for sterility.

\section{Purification ratio and recovery rate}

The original serum averaged 100 units plasminogen per mg. $\mathrm{N}$, whilst the processed material assayed at 5,000 to 10,000 units plasminogen per mg. $N$, representing a purification of 50 to 100 fold. The usual recovery rate of plasminogen was 25 per cent (range 15 per cent to 35 per cent). Equally important from the view of therapeutic use was the fact that inhibitor (expressed as equivalents $\mu \mathrm{g}$ trypsin per mg. $N$ ) had not been concentrated in the processed material (Serum inhibited 50 to 60 $\mu \mathrm{g}$ trypsin per mg. N, whilst this preparation inhibited 30 to $50 \mu \mathrm{g}$ trypsin per $\mathrm{mg} . \mathrm{N}$ ).

\section{Plasmin preparations for intrathecal use}

Earlier work (12 and 13) had shown (a) that while streptokinase was an irritant to the spinal theca, when used in concentrations of 10 to 20 units per $\mathrm{ml}$. cerebrospinal fluid this effect was relatively unimportant, (b) that where low concentrations of streptokinase were used on a solution of fixed plasminogen concentration, the plasmin activity produced was related to the logarithm of the streptokinase concentration, (c) that where the "optimal" concentration of streptokinase (that producing maximum fibrinolytic activity) was used, the plasmin activity was related to the cube root of the plasminogen concentration, and (d) that when the cerebrospinal fluid pathways were obstructed in tuberculous meningitis, the antiplasmin content of the cerebrospinal fluid might rise as high as 15 inhibitor units per $\mathrm{ml}$.

These findings were interpreted as indicating that preparations of plasmin for intrathecal use should be activated with no more than 50 to 100 units streptokinase per ml., and should contain no more plasminogen than was required to produce an enzyme activity of 20 to 25 plasmin units per $\mathrm{ml}$.

Plasminogen diluted to 100 to 150 units plasminogen per $\mathrm{ml}$. and activated with 50 to 100 units streptokinase per ml., fulfilled these requirements. The activity of the various preparations used in this work ranged from 19 to 27 plasmin units per $\mathrm{ml}$. Each $\mathrm{ml}$. of solution then contained 0.02 to $0.01 \mathrm{mg}$. protein $\mathrm{N}$ per ml., and since the clinical dose of the material was found to range from 
4 to $15 \mathrm{ml}$., a single therapeutic injection contained 0.04 to $0.3 \mathrm{mg}$. protein $\mathrm{N}$.

The streptokinase used also contained streptodornase, and this resulted in the plasmin solution containing $\mathbf{5 . 5}$ to 11 units streptodornase per $\mathrm{ml}$. This amount of streptodornase is many times less than that found in our experience to be therapeutically effective, and its presence is not further considered.

\section{RESULTS}

Plasmin solutions maintained at $37^{\circ} \mathrm{C}$ decay at a substantial rate. Figure 1 illustrates two decay curves typical of concentrations used therapeutically. Decay curves similar to those illustrated in Figure 1 were obtained when plasmin and cerebrospinal fluid were mixed and incubated at $37^{\circ} \mathrm{C}$. These data suggested that the duration of effective fibrinolytic activity in vivo was unlikely to exceed 2 to 3 hours if concentrations of enzyme giving 2 to 5 units plasmin per ml. cerebrospinal fluid were used. Experimental confirmation of this point was obtained in six patients.

A further problem was posed by the fact that though one unit of plasmin per $\mathrm{ml}$. will lyse 0.5 mg. of human fibrin at $37^{\circ} \mathrm{C}$ in 30 minutes if the fibrin is in intimate contact with the enzyme, fibrin deposited on the meninges will present a very much smaller surface for enzyme action. Crude experiments with glass models (13) sug-

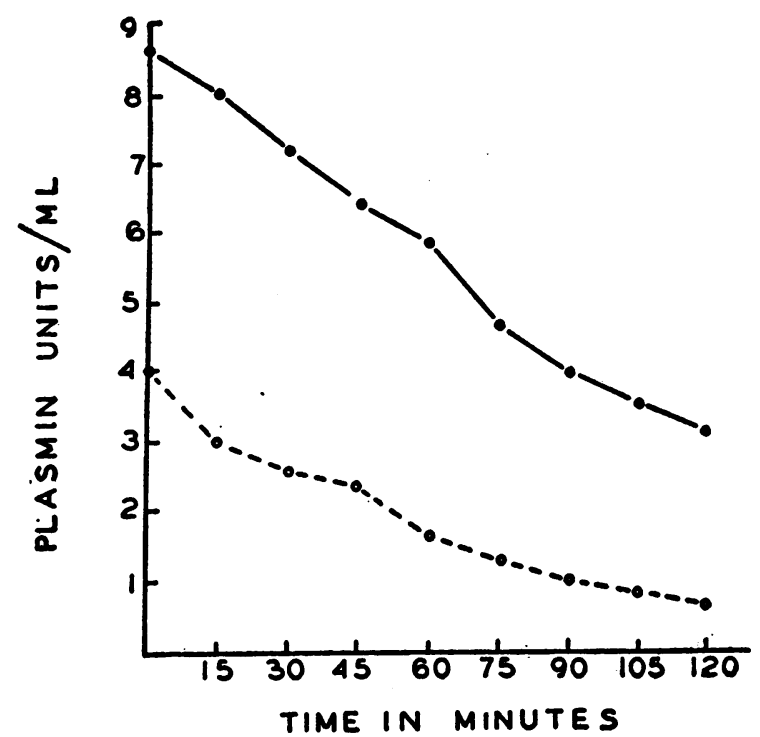

Fig. 1. Decay of Plasmin Activity at $37^{\circ} \mathrm{C}$ - solution containing 8.5 units per ml: $O-O$ solution containing 4.0 units per $\mathrm{ml}$. gested that the dose of plasmin should be increased 3 to 6 fold to compensate for this factor.

Although the amount of fibrin deposited intrathecally cannot be measured, these considerations suggested that fairly high levels of plasmin would be required for successful intrathecal use. It was thought that one unit plasmin per ml. would probably represent a minimal level for successful therapy. In practice sufficient plasmin was injected to provide 2 to 5 plasmin units per $\mathrm{ml}$. cerebrospinal fluid.

\section{Estimation of the dose required for intrathecal treatment}

The "plasmin" used contained plasmin, plasminogen, and streptokinase, whilst the cerebrospinal fluid of patients contained varying amounts of plasminogen, antiplasmin, and low concentrations of anti-streptokinase. The effect of mixing and dilution upon such systems is complex. Furthermore, the composition of the cerebrospinal fluid varies in different portions of the cerebrospinal spaces.

Figure 2 shows that the composition of the patient's cerebrospinal fluid would exert a considerable influence upon the level of fibrinolytic activity produced by the injection of plasmin. The dose suitable for each patient was ascertained by mixing plasmin with varying amounts of cerebrospinal fluid withdrawn from the patient, and after 15 minutes assaying for fibrinolytic activity. The dose was calculated by assuming that the injected enzyme would have mixed after 15 minutes, with $100 \mathrm{ml}$. of cerebrospinal fluid identical in composition with that previously withdrawn from the site of injection. Study of phenolsulphonephthalein dilution curves suggested that the error inherent in this assumption should not exceed \pm 25 per cent. These estimates refer to patients with a free cerebrospinal circulation. Where a spinal block was present the volume of cerebrospinal fluid beneath the block was determined by a phenolsulphonephthalein dilution method, and calculations were based on this detemination. The levels of fibrinolytic activity calculated by these procedures are referred to as the predicted enzyme levels. 


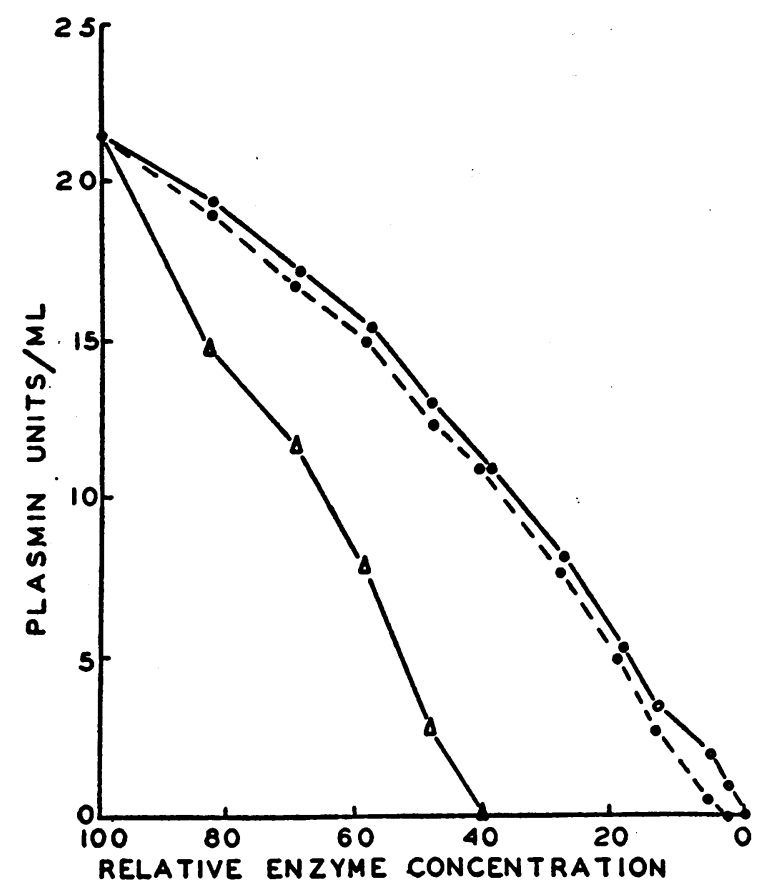

Fig. 2. Enzyme Activity Found when Plasmin is Diluted with Cerebrospinal Fluid Taken from Patients Suffering from Tuberculous Meningitis

O-O Diluted with buffer.

Diluted with cerebrospinal fluid of low inhibitor content (1.2 inhibitor units per ml. 12 plasminogen units per ml.) typical of ventricular cerebrospinal fluid.

$\Delta-\Delta$ Diluted with cerebrospinal fluid of high inhibitor content (15 inhibitor units per $\mathrm{ml}$. 400 plasminogen units per ml.) typical of cerebrospinal fluid showing a Froin syndrome.

Mode of plasmin administration and method of sampling

Puncture of the subarachnoid space was made in the desired location, and the dose of plasmin, usually 4 to $8 \mathrm{ml}$., but on occasion as much as $15 \mathrm{ml}$., was diluted with cerebrospinal fluid in the syringe. The mixture was slowly injected. The syringe remained attached to the needle, and a further two withdrawals and reinjections were made to promote mixing. The needle remained in the subarachnoid space, and 15 minutes later, $5 \mathrm{ml}$. of cerebrospinal fluid was withdrawn for analysis using a fresh syringe.

The time of 15 minutes for sample withdrawal was selected firstly because previous work had shown that plasmin levels were usually highest at this time (13), and secondly because most patients became worried if a needle was left in the subarachnoid space for longer. Moreover, three experiments involving simultaneous ventricular and cisternal sampling had shown that at least with respect to these compartments the difference of plasmin concentrations at the time, was less than 30 per cent.

\section{Correlation of predicted enzyme values and those obtained by sampling}

Figure 3 shows the predicted and actual plasmin levels obtained by sampling after injection of plasmin in 18 patients suffering from tuberculous meningitis and with a free cerebrospinal circulation. There is a reasonable correlation between rise of enzyme concentration predicted from in vitro tests, and rise of enzyme activity found on sampling. The main interest of these figures is to show that consistent and high levels of fibrinolytic activity can be produced in the spinal theca. These findings differ markedly from those with streptokinase, where in vivo levels were under similar circumstances extremely low or altogether absent.

Figure 4 shows the predicted and actual plasmin levels when plasmin was injected below a spinal block. Despite the high level of inhibitor invariably present, reasonable levels of fibrinolytic

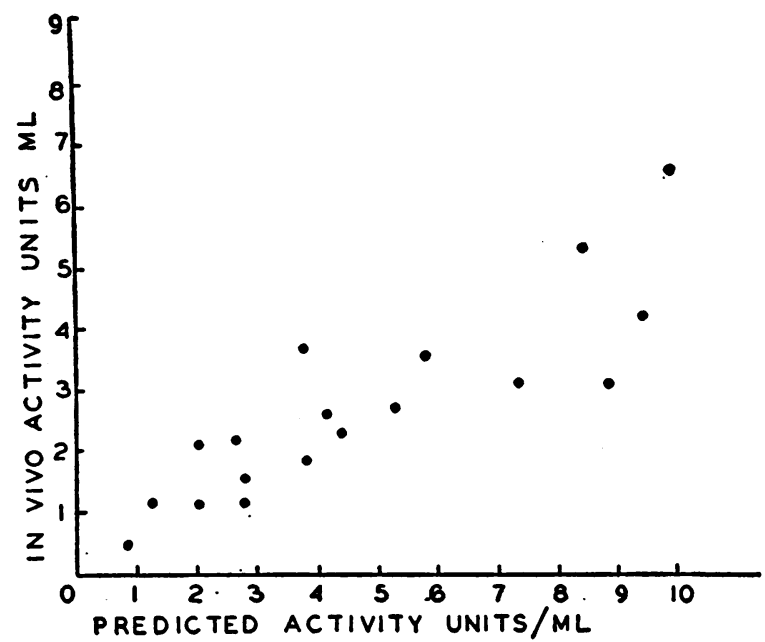

Fig. 3. Comparison of Predicted Enzyme Activity (Abscissa) and the Actual Enzyme Activity Obtained by Sampling (Ordinate)

Cases with unobstructed cerebrospinal circulation (18 observations). 


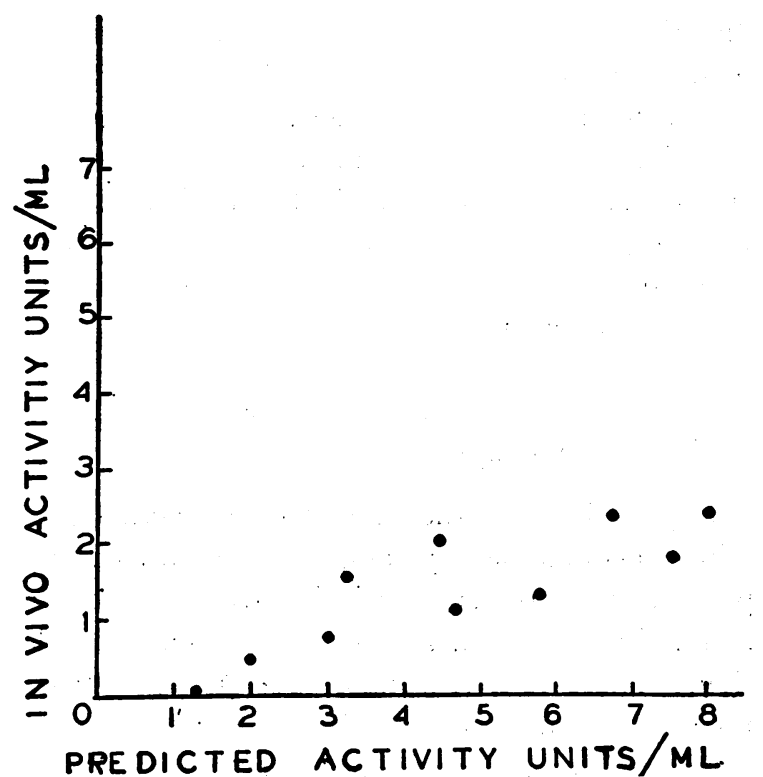

Fig. 4. Comparison of Predicted Enzyme Activity (Abscissa) and the Actual Enzyme Activity Obtained by Sampling (Ordinate)

Cases with spinal block, the enzyme being injected below the block (10 observations).

activity were produced below the block. However, the figures suggest that with the present preparations, high levels of fibrinolytic activity will not be obtained. These figures are in contrast to those obtained with streptokinase, where in all cases under such circumstances there was failure to demonstrate any fibrinolytic activity.

\section{The effect of plasmin upon the composition of the cerebrospinal fluid}

The degree of meningeal irritation produced by the intrathecal injection of plasmin was assessed by examination of the cerebrospinal fluid prior to, and 24 hours after an injection. Thirty-three injections (100 to 400 units plasmin) were so followed, and the results are shown in Table I.

This table demonstrates that though the injection of plasmin on occasion results in a marked pleocytosis and an increased protein content of the cerebrospinal fluid, the degree of meningeal irritation produced, as judged in this manner, is not excessive. The figures for chloride and glucose concentrations were substantially unchanged, and have not been tabulated.

\section{Clinical toxicity}

A total of 83 intrathecal injections of plasmin has been administered to 15 patients, the least number of injections per patient was 3 , and the greatest number 11. Many of these patients were gravely ill (some in coma) at the time of plasmin therapy, so that assessment of the patient's reaction to treatment had to be made on rather uncertain grounds.

Undesirable reactions to treatment have been divided into severe, mild, and not detected. An unexplained rise of temperature exceeding $2^{\circ} \mathrm{F}$ or transient clinical deterioration was taken as indicating a severe reaction in unconscious patients. The same criteria were employed in conscious patients; severe headache, copious vomiting, dizziness or other disabling symptoms were also regarded as indicative of a severe reaction.

Severe reactions numbered 14 (17 per cent of injections). Case 1 died following a cisternal injection of plasmin, though it is probable that her death was coincidental. Case 3 apparently became sensitized to the streptokinase component, and developed a marked pyrexial response to later injections. Case 5 developed a convulsion during one injection. Case 6 developed a temporary spinal fluid block. Case 7 experienced an immediate reaction with mental confusion, tachycardia, and a flushed skin. These case histories are given later.

Any unusual symptom or exaggeration of any symptom previously present was considered a mild reaction. These numbered 20 (24 per cent of injections).

No detectable adverse reaction occurred after 49 injections ( 59 per cent of injections).

The incidence of adverse clinical reaction to

TABLE I

The effect of intrathecal plasmin upon the patients' cerebrospinal fluid (33 observations in patients suffering from tuberculous meningitis, dose 100 to 400 units, second examination 24 hours after the injection) Number of Observations (Change from Patients' Pre-Treatment Level)

\begin{tabular}{lcccc}
\hline $\begin{array}{l}\text { Nature } \\
\text { of } \\
\text { change }\end{array}$ & $\begin{array}{c}\text { Lowered } \\
\text { below } \\
-20 \%\end{array}$ & $\begin{array}{c}\text { Unchanged } \\
\pm 20 \%\end{array}$ & $\begin{array}{c}\text { Raised } \\
+20 \% \text { to } \\
+100 \%\end{array}$ & $\begin{array}{c}\text { Raised } \\
\text { over } \\
+100 \%\end{array}$ \\
\hline Cells & 0 & 12 & 12 & 9 \\
Protein & 6 & 19 & 5 & 3 \\
\hline
\end{tabular}


plasmin appeared to be high, but any untoward symptom was regarded as a reaction. It is possible that a number of the complaints that followed the administration of plasmin were not related to the toxic properties of the preparation itself, but to lysis of intrathecal exudate; indeed some of the reactions to plasmin resembled those seen following the intrathecal injection of tuberculin (18).

No case of clinical jaundice was detected in this series, but further evidence as to the safety or danger of these preparations with regard to the transference of homologous serum jaundice is not available.

\section{Illustrative case histories}

Tubercle bacilli were isolated from the cerebrospinal fluid of all patients described in this section. In all cases the organisms were sensitive to streptomycin. In cases $3,4,5$ and 6 the organisms were shown to be sensitive to isoniazid. All patients were treated with intramuscular and intrathecal streptomycin; cases 1,2 and 7 received in addition $16 \mathrm{Gm}$. p-aminosalycilic acid daily; cases 4, 5 and 6 received either $10 \mathrm{mg}$. per $\mathrm{Kg}$. or $200 \mathrm{mg}$. daily of isoniazid; whilst case 3 received both p-aminosalycilic acid and isoniazid. These case histories were selected to include all patients with severe reactions to plasmin, and also cases with histories where the suggestion of benefit to the patient from plasmin therapy appeared strong. Fifteen patients received plasmin treatment because of some degree of unsatisfactory response to conventional treatment. If case 1 is included, there were two deaths, whilst one patient (case 5) is disabled.

Case 1 (female, age 47), suffering from pulmonary tuberculosis and tuberculous meningitis, had responded poorly to a six months' course of treatment. A ventriculogram had revealed grossly dilated ventricles and an absence of subarachnoid air over the cortex. She was in deep coma, had developed pulmonary edema, and appeared to be in extremis. The first preparations of plasmin had just been made, and she was given a cisternal injection (100 units). Death occurred 30 minutes later.

Post mortem examination revealed extensive pulmonary tuberculosis, advanced signs of chronic tuberculous meningitis with a subtentorial block, and gross hydrocephalus. There was no indication of a misplaced cisternal injection. It is probable that her death was coincidental, especially as the same batch of material was later successfully used in other patients.
Case 2 (female, age 15). Admitted in February, 1952 when she was presented as an ill girl with a high fever, mental confusion, head retraction and a marked Kernig sign. Both fundi showed early papilledema with mimerous choroidal tubercles. Coarse rales were heard throughout the chest and the chest $\mathrm{X}$-ray revealed gross miliary shadowing.

By mid-April her condition had improved, but at this time she developed a spinal block. Two injections of plasmin (300 units) were given below the block, after which the block resolved. This relief was only temporary, and ten days later the cisternal pressure rose to $300 \mathrm{~mm} .+$, the spinal block reappeared, she lapsed into deep coma and gross papilledema in both fundi. A ventriculogram revealed generalized ventricular dilatation and an absence of air over the cortex. Simultaneous ventricular and cisternal puncture revealed that the ventricles communicated freely with the cisterna magna. The diagnosis of subtentorial block appeared to be certain.

Four injections of plasmin (200 units each) during the next eight days via the ventricular route produced a dramatic change in her clinical condition. The gross papilledema disappeared, she recovered from coma, and became rational, mentally alert, and cheerful. There was a gradual disappearance of pyrexia, though the spinal fluid block persisted.

Three weeks after the last plasmin injection her temperature suddenly rose to 104 , she developed tachycardia of 200 , and died 24 hours later.

Post mortem examination revealed extensive miliary tuberculosis, which had apparently responded little to treatment. Numerous vascular lesions due to tuberculous arteritis were found in the brain stem and upper cervical cord, and these lesions were probably the cause of her death. Careful examination of the tentorial opening showed that although it was partly occluded by exudate, there was adequate and free communication above and below the membrane. The ventricular system was of normal dimensions.

Case 3 (female, age 30). Admitted in August, 1952 when her clinical condition was grave; she was drowsy, irrational and showed marked signs of meningeal irritation. A left external rectus palsy was present, but the fundi were normal. A chest $\mathrm{X}$-ray revealed the classical "snow storm" appearance of gross miliary tuberculosis and numerous scattered coarse rales were audible on physical examination.

Her response to treatment was slow, but at the end of one month she was rational, the external rectus palsy had disappeared, and rales were no longer heard over the chest. She continued to improve during the next three weeks, but at the end of September, 1952 she developed a spinal fluid block. Early in October she developed papilledema, and became comatose, whilst the cisternal pressure, which had previously averaged $150 \mathrm{~mm}$., suddenly rose, and consistently exceeded $300 \mathrm{~mm}$.

Burr holes were drilled, and one week later during which time her condition had further deteriorated and 
she had developed gross papilledema, a ventriculogram was performed. The ventriculogram revealed some degree of generalized ventricular dilatation, and an absence of air over the cortex. Simultaneous cisternal and ventricular punctures demonstrated free communication between the ventricles and the cisterna magna, which confirmed the diagnosis of subtentorial block.

She was treated with eight injections of plasmin over the next three weeks; 200 to 300 units were given upon each occasion by the ventricular route. Following the second injection and subsequently there was rapid clinical improvement. At the end of the course she was fully conscious and rational, and the ventricular pressure averaged $150 \mathrm{~mm}$. A ventriculogram demonstrated the ventricles to be of normal size, whilst air was seen over the cortex. The papilledema had greatly decreased, though the disc margins were still abnormal.

During November, 1952 three injections of plasmin were given by the lumbar route with the intention of resolving the spinal fluid block. Each injection was followed by increasing pyrexia and systemic upset. It was thought that the initial course of injections had sensitized her to streptokinase, a conclusion supported by the fact that she tolerated an intrathecal injection of plasminogen without disturbance. She was discharged from the hospital in April 1953, and has since remained well, though her spinal fluid block has persisted.

Case 4 (female, age 30). Admitted in April, 1953. Her general condition was good. Examination revealed a left external rectus palsy and signs: of meningeal irritation. The chest $\mathrm{X}$-ray showed small, apparently inactive adult type tuberculous foci at both apices.

A week after admission she developed a left superior oblique palsy, and papilledema appeared. The cerebrospinal fluid pressure remained low, but she became irrational and drowsy, and began to vomit frequently. A tentative diagnosis of basal cistern block was made.

Six weeks after admission all signs had progressed and she was gravely ill and had lost much weight. Her cerebrospinal fluid pressure was still low, and the diagnosis of basal cistern block was now felt to be very likely. Plasmin (100 units) was administered by the cisternal route, shortly after which she complained of severe pain in the neck and vomited copiously. The next day the superior oblique palsy had disappeared.

Two days later 200 units of plasmin were given by the cisternal route without upset. Three days later 200 units were administered. This injection was followed one hour later by marked dizziness, copious vomiting and a temperature of $102^{\circ} \mathrm{F}$. She recovered in about eight hours and 24 hours later the left external rectus palsy had disappeared. Twelve days after the start of plasmin therapy her general condition was much improved, she was rational, eating well, vomiting had ceased, and the papilledema had practically disappeared, though she still complained of diplopia upon looking to the left. Her cisternal fluid protein dropped from a level of $300 \mathrm{mg}$. per cent to $150 \mathrm{mg}$. per cent during the period of therapy.

Her clinical progress has since been excellent, she has recovered her pre-treatment weight, and binocular vision has slowly been achieved. She was discharged from hospital during November, 1953.

Case 5 (female, age 35 ). This patient, a gravely ill woman, suffered also from advanced renal and vesical tuberculosis, when she was admitted during December, 1952.

One week after admission papilledema appeared followed by paralysis of the left lateral rectus and left inferior oblique muscles. Despite a low cerebrospinal fluid pressure, the papilledema increased rapidly, becoming gross at the end of four weeks. At this time the cerebrospinal fluid pressure suddenly rose to over 300 mm., the patient's condition worsened, and she began to vomit frequently. The diagnosis of basal cistern block complicated by a recent subtentorial block was thought to be likely, but owing to technical difficulties, satisfactory air injection studies were not completed. However test of phenolsulphophenolthalein excretion from the ventricles was decreased, only 23 per cent of the total dose being excreted in two hours.

On the thirteenth of January; 1953, she was given 400 units of plasmin by the lumbar route without incident, and on the next day she seemed better. On the sixteenth of January, 400 units of plasmin were given by the ventricular route. During the injection she experienced a transient convulsion, the pupils became dilated and the right arm twitched. She recovered after three minutes but vomited later. On January nineteenth, the inferior oblique palsy had disappeared, and an additional 200 units of plasmin were given by the lumbar route without incident. On the twenty-sixth her general condition was greatly improved, and the papilledema had regressed to a marked degree. By the twenty-third of February the optic fundi were nearly normal, the cerebrospinal fluid pressure was $200 \mathrm{~mm}$., and the left rectus palsy had disappeared so that binocular vision was possible. By midFebruary she was rational, and the urinary excretion rate of phenolsulphophenolthalein injected into the ventricles had returned to normal.

In April symptoms and signs of optic atrophy were found, and by the end of June visual acuity was reduced to finger counting at one yard. Since this time her vision has improved, but the loss of visual acuity is still severe.

By July her cerebrospinal fluid was within normal limits and has remained so. The renal and vesical tuberculosis, however, progressed and she has since had her ureters transplanted into a blind ileostomy because of a contracted bladder.

Case 6 (female, age 18). Admitted during February, 1953. Her general clinical condition was good, though early papilledema was present.

In April the papilledema, which had been slowly increasing in degree, had become gross, and her condition commenced to deteriorate, although the cerebrospinal fluid pressure remained low. A diagnosis of basal cistern block appeared probable. She had also complained of severe pain in the legs, which had been attributed to involvement of the posterior roots by exudate.

Two hundred and twenty units of plasmin were given 
by the lumbar route without discomfort. Four hours later she complained of severe aching in the chest, examination showed her to be tender over the thoracic spines, and light percussion over these spines intensified the chest pain. She was given analgesics and the pain disappeared.

Three days later the papilledema had decreased, and her general condition had improved. An injection of 110 units of plasmin was given by the lumbar route. Symptoms similar to those experienced earlier developed after three hours, but this time the intensity of the pain was greater. The next day lumbar puncture revealed a Froin syndrome in the cerebrospinal fluid and a negative Queckenstett response; but 24 hours later these anomalies were absent, and the lumbar cerebrospinal fluid protein was $600 \mathrm{mg}$. per cent, which was the same as before plasmin therapy.

One further injection of 150 units plasmin was given, but upon this occasion the injection was tolerated well. During the fortnight's treatment with plasmin the papilledema decreased greatly (from 4 plus to 1 plus). The pains in the legs were entirely relieved following the third plasmin injection. Her clinical condition was greatly improved, and her subsequent progress was satisfactory. There was no impairment of visual acuity. She was discharged from hospital in October, 1953.

Case 7 (female, age 23). Three months' treatment had produced a substantial improvement in this patient's condition. She had complained, for three weeks, of severe pains in the legs, for which no cause could be found, and which was controlled only by large doses of analgesics. It was thought that the lumbar sensory roots were surrounded by exudate.

Two minutes after a lumbar injection of 200 units of plasmin, she became dizzy, shouted that she was dying, sweated profusely, developed a flushed skin, and her pulse rate rose from 70 to 160 . An injection of sodium phenobarbitone produced rapid relief, and 30 minutes later she was apparently well.

This particular batch of material had been buffered with $0.005 \mathrm{M}$. citrate buffer. The use of citrate buffer was stopped, since temporary depression of the ionized calcium in the cerebrospinal fluid could have been responsible for her symptoms. This patient later tolerated two injections of plasmin buffered with $0.005 \mathrm{M}$ phosphate without complaint. The pains in the legs disappeared after the second injection. She has since been discharged from hospital and remains well.

\section{DISCUSSION}

The findings reported here show that high levels of fibrinolytic activity can be safely produced intrathecally by the injection of plasmin. Further, it is possible to produce reasonable levels of fibrinolytic activity with plasmin even when the cerebrospinal fluid shows a Froin syndrome, a condition previously shown to be a bar to the production of fibrinolytic activity by injections of streptokinase (13).

The purpose of the clinical investigation was to determine whether plasmin would lyse tuberculous exudate in vivo. Subtentorial and basal cistern blocks were selected as suitable test lesions since both are known to be caused by exudate formation, the presence or absence of either complication can be diagnosed during life, and the usual outcome of the untreated lesion is unfavorable.

The case histories indicate that the levels of plasmin, which can be attained by intrathecal injection, are capable of lysing exudate in vivo. Cases 2 and 3 showed regression of hydrocephalus under treatment, an extremely rare occurrence. Lorber (19), who cites the literature fully, believes that hydrocephalus either remains stationary or progresses, despite the clinical improvement that sometimes occurs. He observed only one patient in whom there was evidence that the degree of hydrocephalus regressed. The diagnosis of basal cistern block during life is difficult, but the evidence points strongly toward this diagnosis in cases 4, 5 and 6. All made an apparently striking improvement on plasmin, though case 5 eventually developed optic atrophy.

The treatment of spinal fluid block was regarded as a secondary aim, since initially, the dangers of this condition to the patient were not fully appreciated. Poor results were obtained when treating spinal fluid block with plasmin. Ten attempts (i.e., single injections) to lyse spinal blocks in three patients were made with two temporary successes. The reasons for this difficulty are readily appreciated from post mortem study, since the surface available for enzyme action is extremely small, compared to the total volume of the block.

Plasmin having been shown to be effective in vivo, the basis and timing of treatment required examination. Subtentorial and basal cistern block are most dangerous lesions causing death, intellectual deterioration, blindness, and other sequelae. It is clearly unjustifiable to allow patients to undergo the hazards inseparable from the developed lesion, if prophylactic treatment is feasible. Brooks, Fletcher, and Wilson (2) have recently shown that exudate formation around the spinal cord leading to tuberculous arteritis is responsible for the appearance of transverse myelitis found in 
this disease. They showed that, where exudate formation was gross, the frequency and severity of the lesions were notably increased. Here, too, prophylactic treatment is indicated, particularly in view of the indifferent results obtained by the treatment of established spirial block.

It is believed (20) that the use of isoniazid has greatly improved results in the treatment of tuberculous meningitis, and our experience supports this view. However, the need for some means for removal of exudate is underlined by the fact that four patients in this series and three patients cited by Brooks, Fletcher, and Wilson (2) were treated with streptomycin and a dose of isoniazid that gives satisfactory intrathecal levels (21).

Prophylactic treatment would have the further advantage that small doses of plasmin (100 to 200 units) would be adequate, and that the larger doses of 400 or more : units would no longer be necessary. Fibrinolytic enzymes cannot lyse organized tissue, and thus in every patient the earlier that treatment can be started, the better should be the end results. Further, prophylactic treatment should lead to more favorable results than treatment of the established lesion, since the surface available, for enzyme action, and the access of the enzyme to the surface will both greatly diminish once the cerebrospinal fluid circulation is partially occluded.

The preparations of plasminogen used in this study were of a comparatively crude nature. Christensen and Smith (22), by means of their acid extraction process, have prepared material 5 to 10 times as pure, and Kline (23) by a modification of the Christensen process claims even greater purity. Unfortunately, material prepared by acid extraction has so far proved almost impossible to sterilize, owing to its physical state of dispersion. It is probable that much of the difficulty in completely activating solutions of plasminogen is due to the impurity of the streptokinase available, and further improvements in the preparation of this material would be helpful. The recent review of Christensen (24) provides an able discussion of the controversy concerning the mechanism of plasminogen activation.

The present preparations, despite their imperfections, would appear to fulfill the essential needs for clinical work. They were developed with the purpose of treating tuberculous meningitis, but it is clear that their use could be extended to the treatment of other forms of meningitis, where exudate formation is troublesome. Indeed, plasmin would appear to have a wide field of usefulness in a variety of pathological states, when, for one reason or another, in vivo streptokinase activation is not feasible.

\section{SUMMARY}

1. A method for the preparation of partially purified plasminogen is described. The preparations contained 5,000 to 10,000 units plasminogen per mg. N. This material after sterilization and activation with streptokinase was suitable for intrathecal use.

2. Eighty three injections of plasmin were administered to 15 patients suffering from tuberculous meningitis. The incidence of systemic reaction was apparently high, but the degree of meningeal reaction, as judged by changes in the composition of the cerebrospinal fluid, was not great.

3. The injection of plasmin gave rise to high levels of intrathecal fibrinolytic activity in patients suffering from tuberculous meningitis. This finding contrasted sharply with the results obtained following the injection of streptokinase.

4. Patients suffering from subtentorial and basal cistern block were treated with plasmin to determine whether tuberculous exudate would undergo lysis in vivo. The results indicated that exudate had undergone lysis in vivo.

5. The clinical results obtained suggested that the use of plasmin as a therapeutic agent should be further investigated.

\section{ACKNOWLEDGMENTS}

I am indebted to Professor Sir Alexander Fleming and Professor Robert Cruikshank for much encouragement and helpful criticism. I also thank Dr. W. D. W. Brooks for advice in the clinical management of the cases; $\mathrm{Mr}$. J. Tobar for excellent technical assistance in the laboratory; and the Director of Lederle Laboratories Division for a generous gift of "Varidase" streptokinase-streptodornase and supplies of "Clotting Globulin." This work was completed whilst holding a Merck International Fellowship at the Bellevue Medical Center, New York.

\section{REFERENCES}

1. Auerbach, G., Tuberculous meningitis correlation of therapeutic results with the pathogenic and patho- 
logical changes. II: Pathological changes in tuntreated and treated cases. Am. Rev. Tuberc., 1951, 64, 419.

2. Brooks, W. D. W., Fletcher, A. P., and Wilson, R. R., The transverse myelitis of tuberculous meningitis: A clinical and pathological study. Quart. J. Med., 1954 (in press).

3. Doniach, I., Changes in the meningeal vessels in acute and chronic (streptomycin-treated) tuberculous meningitis. J. Path. \& Bact., 1949, 61, 253.

4. Winter, W. J., The effect of streptomycin on the pathology of tuberculous meningitis. Am. Rev. Tuberc., 1950, 61, 171.

5. Cathie, I. A. B., Bacterial fibrinolysin, its possible therapeutic application in tuberculous meningitis. J. Clin. Path., 1949, 2, 73.

6. Cathie, I. A. B., Streptomycin-streptokinase treatment of tuberculous meningitis. Lancet, 1949, i, 441.

7. Cathie, I. A. B., and MacFarlane, J. C. W., Adjuvants to streptomycin in treating tuberculous meningitis in children. Lancet, 1950, ii, 784.

8. Eadie, M. B., Personal Communication, 1952.

9. Lorber, J., Streptokinase as an adjunct in the treatment of tuberculous meningitis. Lancet, 1951, i, 1334.

10. Christensen, L. R., and MacLeod, C. M., A proteolytic enzyme of serum: Characterization, activation and reactions with inhibitors. J. Gen. Physiol., 1945, 28, 559.

11. Tillett, W. S., and Sherry, S., The effect in patients of streptococcal fibrinolysin (streptokinase) and streptococcal desoxyribonuclease on fibrinous, purulent, and sanguinous pleural exudations. J. Clin. Invest., 1949, 28, 173.

12. Fletcher, A. P., The measurement of the components of the plasminogen-plasmin system in biological fluids. Biochem. J., 1954, 56, 677.
13. Fletcher, A. P., Intrathecal fibrinolysis with streptokinase in tuberculous meningitis. J. Clin. Invest., 1954, 33, 69.

14. Hamburger, M., and Biehl, J. P., Some effects of injecting sterile solutions of streptokinase-streptodornase into the subarachnoid space of normal rhesus monkeys. J. Clin. Invest., 1953, 32, 391.

15. Christensen, L. R., Methods for measuring the activity of components of the streptococcal fibrinolytic system and streptococcal desoxyribonuclease. J. Clin. Invest., 1949, 28, 163.

16. Kekwick, R. A., MacKay, M. E., and Record, B. R., Fractionation of human plasma with ether. $\mathrm{Na}$ ture, 1946, 157, 629.

17. MacFarlane, A. S., Behavior of lipoids in human serum. Nature, 1942, 149, 439.

18. Fletcher, A. P., Intrathecal tuberculin in tuberculous meningitis. Lancet, 1951, ii, 290.

19. Lorber, J., Studies of the cerebrospinal fluid circulation in tuberculous meningitis in children. Part II. A review of 100 pneumoencephalograms. Arch. Dis. Childhood, 1951, 26, 28.

20. Torres-Gost, J., The treatment of tuberculous meningitis: with streptomycin and isoniazid. Lancet, 1953, ii, 693.

21. Fletcher, A. P., C.S.F.-isoniazid levels in tuberculous meningitis. Lancet, 1953, ii, 694.

22. Christensen, L. R., and Smith, D. H., Jr., Plasminogen purification by acid extraction. Proc. Soc. Exper. Biol. \& Med., 1950, 74, 840.

23. Kline, D., The purification and crystallization of plasminogen (profibrinolysin). J. Biol. Chem., 1953, 204, 949.

24. Christensen, L. R., The streptokinase-plasminogen system in Streptococcal Infections, Editor, Maclyn MacCarty, Symposia of the Section on Microbiology. The New York Academy of Medicine, No. 7, New York, Columbia University Press, 1954. 